هبلة كلية الآثا ابي بامعة بهورسعيد

\title{
موقف المدرس من أصول النحو
}

إعداد الباحث

مصطفى عبد المكيم حامد موسى خبير 
أصول النحو، قال أبو البركات الأنباري (ت/أ/OOV هـ) عنها: "أصول النحو أدلة النحو التي تفرعت

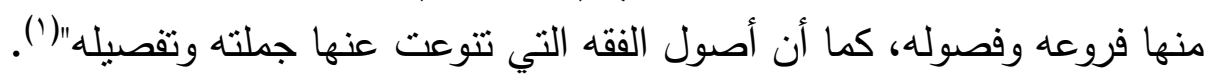
وقال السيوطي: "أصول النحو علم يبحث فيه عن أدلة النحو الإجمالية من حيث هي أدلته، وكيفية الاستدلال بها، وحال المستدل" (؟). وإختلف العلماء في أدلة النحو:

فقال أبو البركات الأنباري في لمع الأدلة: "أدلة النحو ثلاثة: نقل، وقياس، واستصحاب

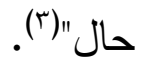
فذكر الاستصحاب، ولم يذكر الإجماع، وكأنه لم يعترف به دليلا من أدلة النحو. ونقل السيوطي في الاقتراح (ء) عن ابن جني أن أدلة النحو ثلاثة: السماع والإجماع والقياس. وبالنظر فيما ذكره ابن جني وأبو البركات الأنباري تنين أن أصول النحو أربعة هي: السماع والقياس، والإجماع، واستصحاب الحال.

(1) ينظر: لمع الأدلة في أصول النحو لأبي البركات الأنباري، تحقيق: سعيد الأفغاني (•^) مطبعة الجامعة

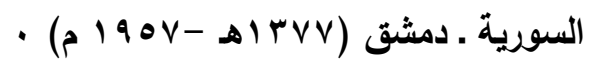

(r) ينظر: الاقتراح في علم أصول النحو للسيوطي، تحقيق: عبد الحكيم عطية (r) دار البيروتي، دمشق .

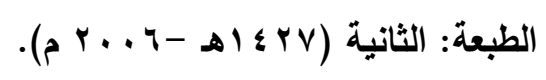

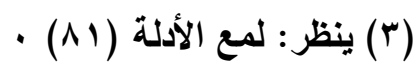

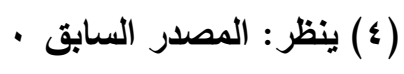




\section{فائدة أدلة النحو:}

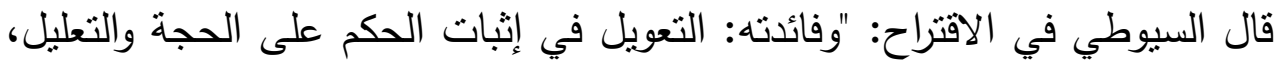

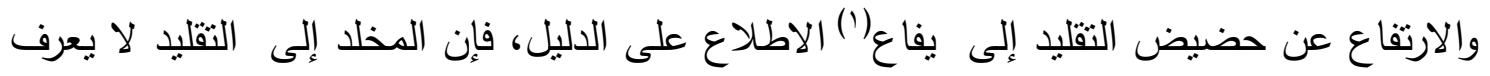

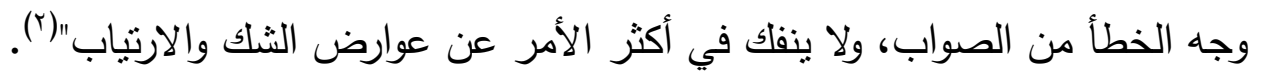

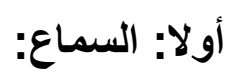

وهو "الكلام العربي الفصيح المنقول بالنقل الصحيح الخارج عن حد القلة إلى حد الكثرة"(ז).

$$
\text { وقال السيوطي في الاقتراح: "ما ثبت في كلام من يوثق بفصاحته"(؛). }
$$

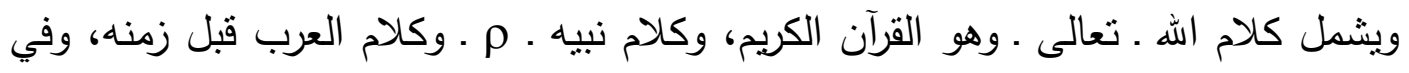

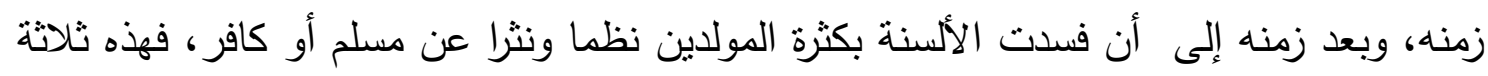

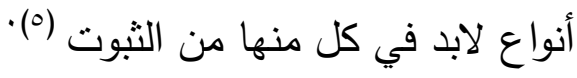

$$
\begin{aligned}
& \text { 1 ـ القرآن الكريم: }
\end{aligned}
$$

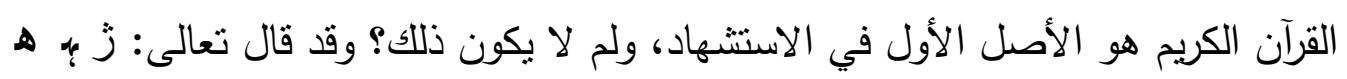

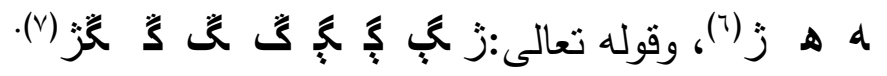

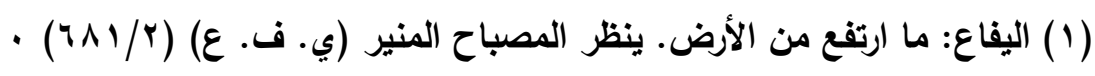

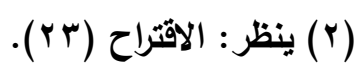

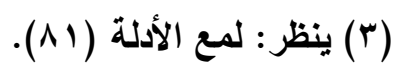

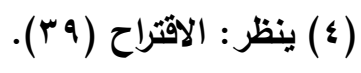

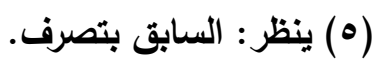

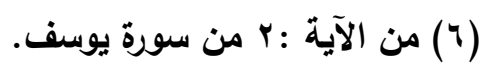

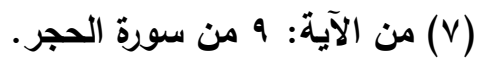


وقد عجز أرياب الفصاحة والبيان عن أن يأتوا بمثله، أو بعشر سور مثله، أو بسورة من

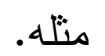
وهو النص الذي لم تمند إليه يد التبديل والتحريف، وقد درج النحاة منذ العهد الأول للتأليف اللغوي على الاستشهاد به وبقراءاته المختلفة.

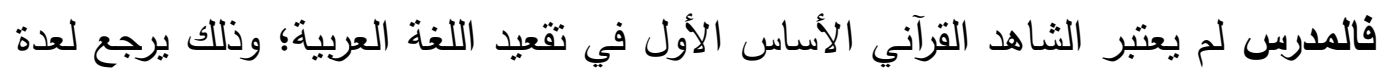

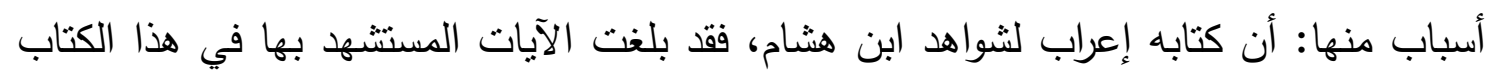
انثين وعشرين آية.

ومع قلة الاستشهاد به عنده؛ فهو _رحمه اللهـ_ لم يقتصر في الكتاب على الاستشهاد بالآيات القرآنية على القواعد النحوية فحسب، بل تعددت طرق الإد الاستشهاد بها.

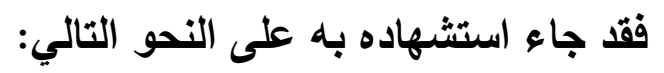
1 - آيات ذكرت مفردة لإثبات حكم أو قضية، ومن أمثلة ذلك الكئ قوله ، وهو يتحدث عن أقسام اللام في هذا الثاهد:

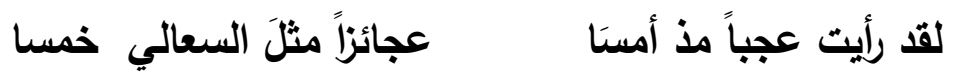

يقول: "اعلم أن (اللام) على قسمين: عاملة، وغير عاملة، فالثانية: على أقسام: أحدها لام

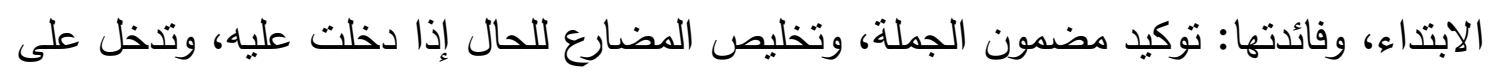

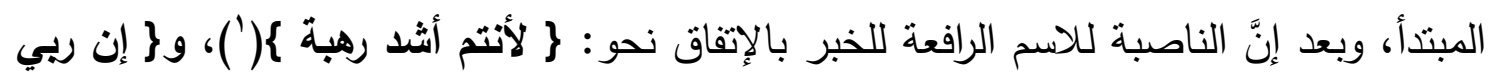

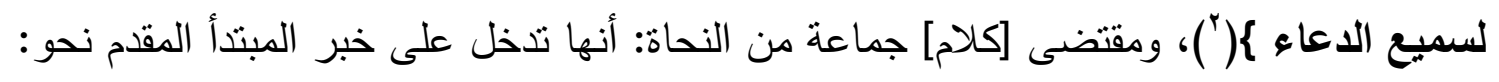

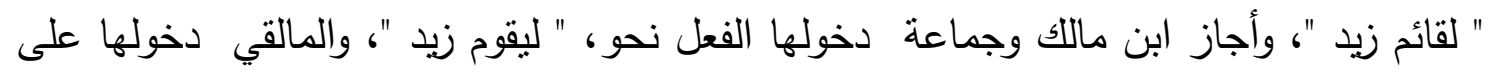

(') سورة: ( الحشر ) الآية رقم (r ( ) ) . 
الماضي الجامد نحو : \} لبئس ما كانوا يفعلون \{(')، وذهب بعضهم إلى أنها تدخل على الفعل

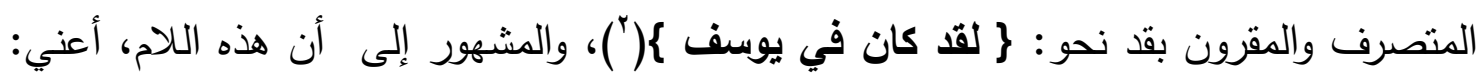
الداخلة على الفعل المتصرف المقرون بقد لام القسم، ومقتضى كلام الثيخ أبي حيان أنه يجوز

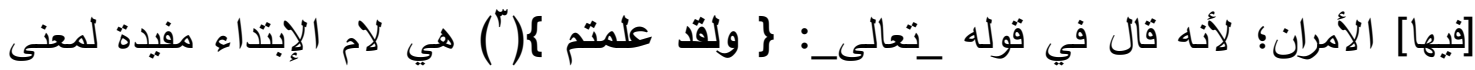

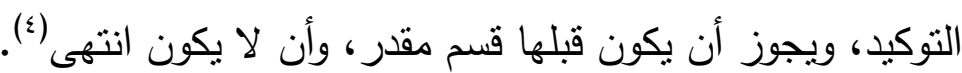
r - آيات ذكرها مع شواهد أخرى كالثعر، وغيره من أقوال العرب؛ لإثبات حكم أو قضية، أو لنفي حكم أو قضية، ومن ذلك:

\section{- قوله في إعرابه لهذا الثاهد:}

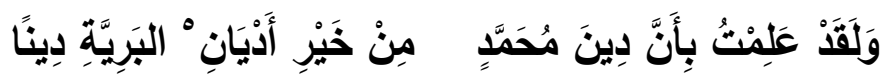

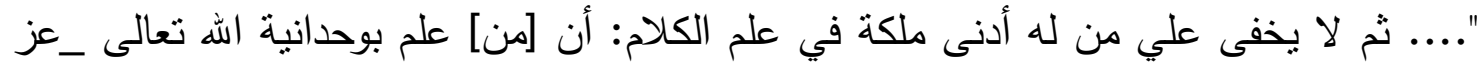
وجل_، وبحقيقة دين محمد _صلى الله عليه وسلم_ ولم يقر بذلك كما وقع لكثير من المنافقين لم

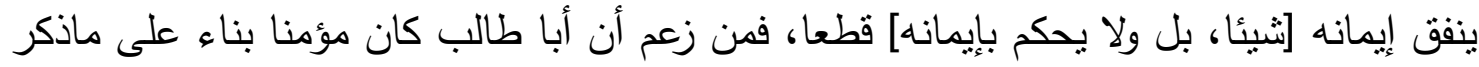

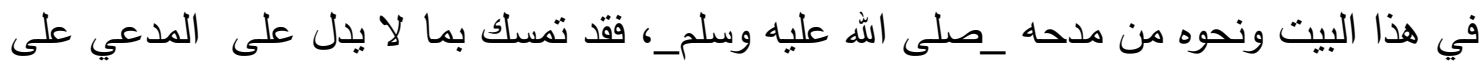

(') سـورة: ( المائدة ) الآيـة رقم (r T)، ينظر رأيسه في: رصف المباني في شرح حروف المعاني، للمـالقي

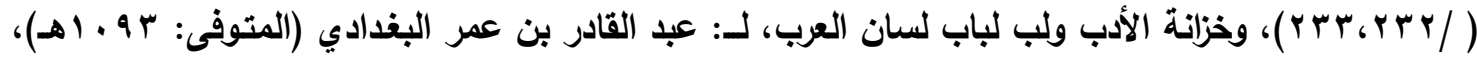
.$(07 / 1 \cdot)$

(") سورة: ( يوسف ) الآية رقم (V). ينظر: جامع الدروس العربية، لـ: مصطفى بن محمد سليم الغلايينى

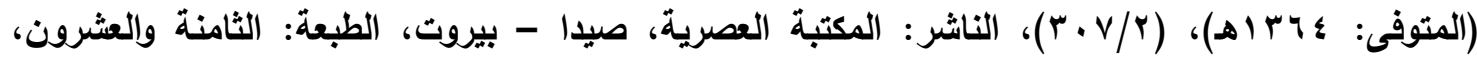

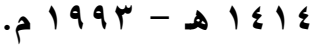

$$
\begin{aligned}
& \text { (") سورة: ( البقرة ) الآية رقم (10) . }
\end{aligned}
$$

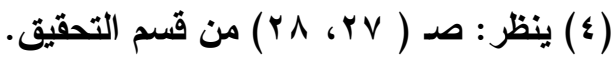


أنه _صلى الله عليه وسلح_ لما أراد من أبي طالب الثهادة حين حضرته الوفاة، فقال له: ياعمّ، قل: _لا إله إلا الله_أثهد للك بها يوم القيامة فقال له: لولا أن تعيرني قريش يقولون: أنه حمله

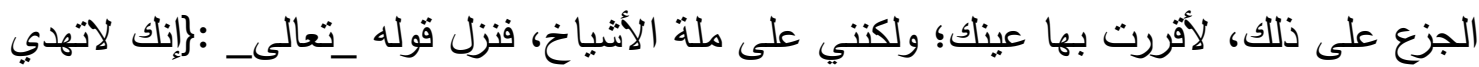

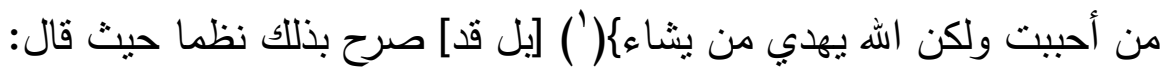

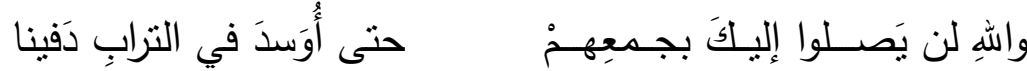

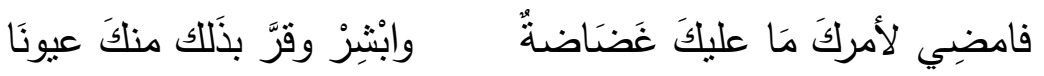

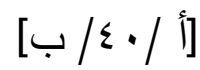

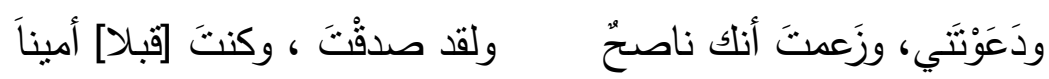

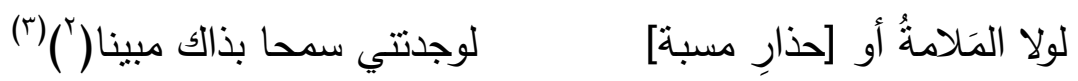
r- موقفه من الاستشهاد بالقراءات القرآنية: القراءات جمع قراءة، وهي في اللغةة: مصدر سماعي لـ(قَرَاً).

وفي الاصطلاح: "مذهب يذهب إليه إمام من أئعة القراء مخالفا به غيره في النطق بالقرآن

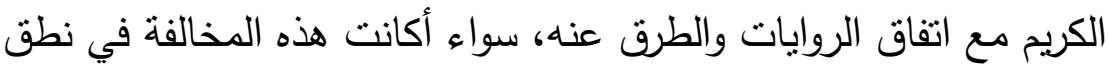
الحروف أم في نطق هيئاتها"(؛).

(') (') من سورة: القصص، آية رقم (ه0) . (†) الأبيات من بحر الكامل، وهي لأبي طالب في ديوانه، ( / (9) يدعو النبي صلى الله عليه وسلم أن يصدع

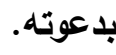

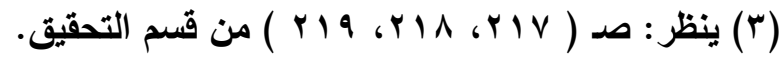

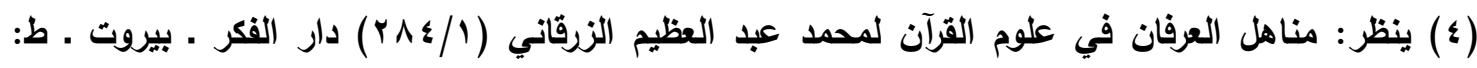

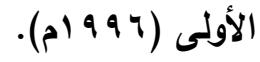


هذا، وكل ما ورد أنه قرئ به جاز الاحتجاج به في اللغة العربية، لا فرق في ذللك بين

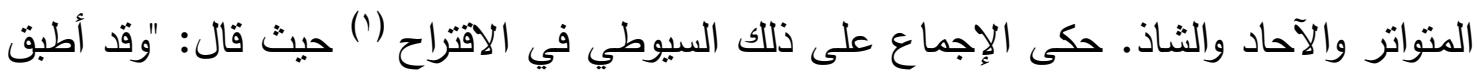

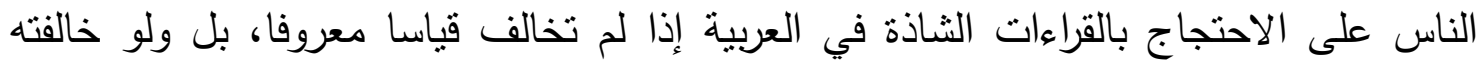
يحتج به في منل هذا الحرف بعينه، وإن لم يجز القياس عليه، كما يحتج بالمجمع على وروده" (؟). هذا، والمدرس لم يستشهد في اعرابه لثواهد القطر بالقراءات القرآنية إلا بقراءة واحدة في

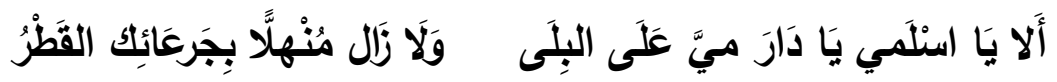

فيقول: " (ألا): حرف تتبيه، و (با): يحتمل أن تكون حرف تتبيه؛ فتكون مؤكدة لألا، ويحتمل

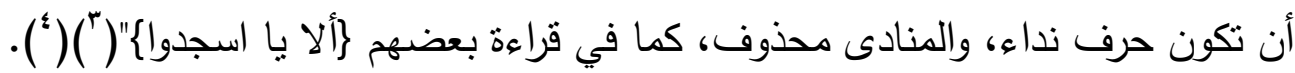

r- الحديث الثريف وموقف المدرس منه:

الحديث هو الأصل الثالث من أصول الاستشهاد بعد القرآن الكريم، والقراءات القرآنية، وقد

اختلف العلماء في الاستتهاد به إلى ثلاهثة مذاهب:

المذهب الأول: وهم المانعون مطلقا وقد جرى على هذا المذهب أبو حيان وشيخه أبو الحسن

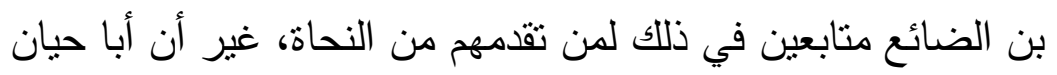

استشهد به في التنييل والتكميل، وارتنشاف الضرب(').

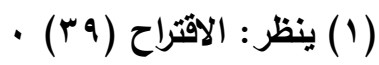 \\ -

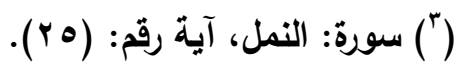

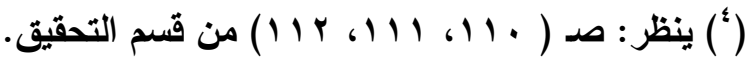

العقد الثمالمش لمشر / يوليه - 19. مه 


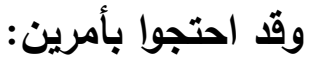

أحدهما: أن الأحاديث لم تتقل كما سمعت من النبي ـ عليوسلاله . وإنما رويت بالمعنى.

وثُانيهما: أن أئعة النحو المتقدمين من المصرين لم يحتجوا بشيء منه.

ورد الأول . على تقدير تسليمه ـ بأن النقل بالمعنى إنما كان في الصدر الأول قبل تدوينه في

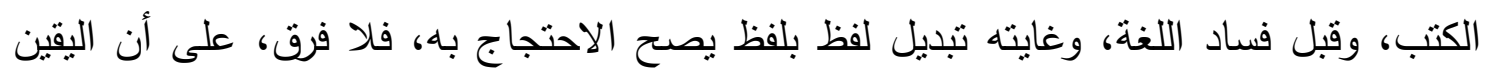

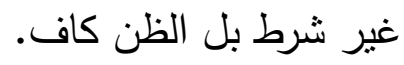

\section{ورد الثاني: بأنه لا يلزم من عدم استدلالهم بالحديث عدم صحة الاستدلال به"(؟).}

وعللوا المنع بأمرين (†):أحدها: جواز روايته بالمعنى، وهذا يؤكد أن بعض الأحاديث التي

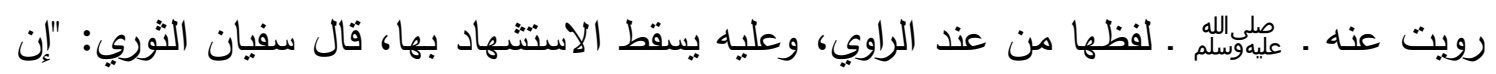
قلت لكم إني أحدثكم كما سمعت فلا تصدقوني". ثانيهما: وقوع اللحن كثثرا فيما روى من الأحاديث؛ لأن كثيرا من الرواة كانوا غير عرب بالطبع.

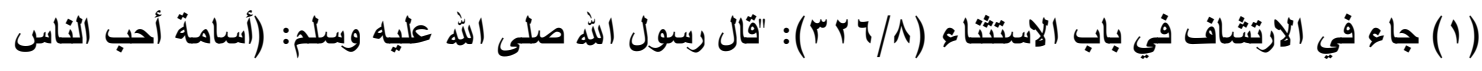

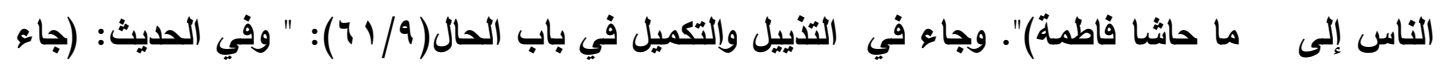
رسول الله علي فرس سابقا)." وغير ذلك. فأبو حيان بريء مما نسب إليه.

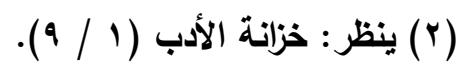

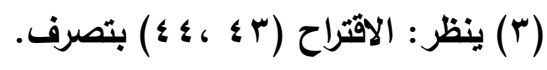


ورد الأول . على تقدير تسليمه ـ بأن النقل بالمعنى إنما كان في الصدر الأول قبل تدوينه في الكتب، وقبل فساد اللغة، وغايته تبديل لفظ بلفظ يصح الاحتجاج به، فلا فرق، على فلى أن اليقين

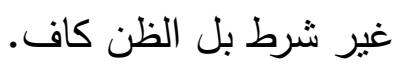

ورد الثاني: بأنه لا يلزم من عدم استدلالهم بالحديث عدم صحة الاستدلال به"(').

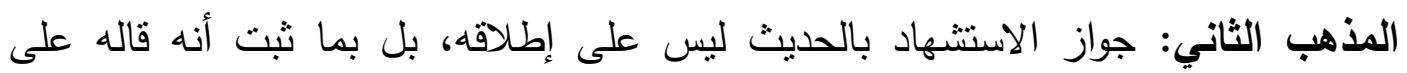
اللفظ، وذلك نادر جدا، إنما يوجد في الأحاديث القصار على قلة ـ أيضا ـ فإن أغلب الأحاديث

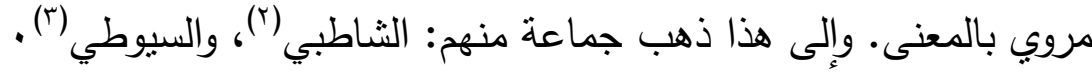
وقد أخذ به مجمع اللغة العربية بالقاهرة ونصه: "اختلف علماء العربية في الاحتجاج

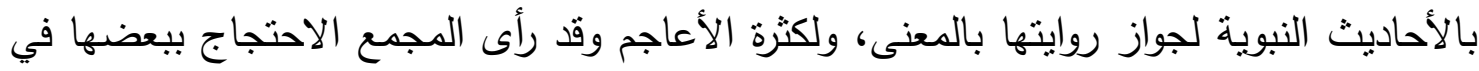
أحوال خاصة مبينة فيما يأني: ا ـ لا يحتج في العربية بحديث لا يوجد في الكتب المدونة في الصدر الأول، كالكتب الصحاح الستة فما قبلها. r ـ يحتج بالحديث المدون في هذه الكتب الآنفة الذكر على الوجه الآتي: أ ـ الأحاديث المتواترة المشهورة. ب ـ الأحاديث التي تستعمل ألفاظها في العبادات. ج . الأحاديث التي تعد من جوامع الكلم.

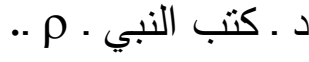
هـ ـ الأحاديث المروية لبيان أنه ـ م ـ كان يخاطب كل قوم بلغتهم.

(1) (1) ينظر : خزانة الأدب (1 / (9).

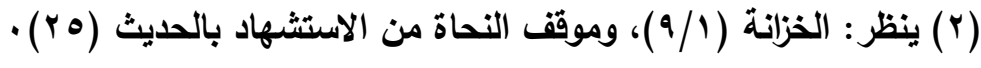

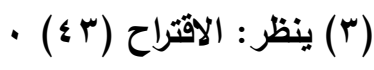


و ـ الأحاديث التي عرف من حال رواتها أنهم لا يجيزون رواية الحديث بالمعنى منل: القاسم بن

$$
\text { محمد، ورجاء بن حيوه، وابن سيرين. }
$$

ز ـ الأحاديث المروية من طرق متعددة وألفاظها واحدة"(') ونئ.

المذهب الثالث: جواز الاحتجاج بالحديث مطلقا، وإليه ذهب جماعة، وفي مقدمتهم ابن

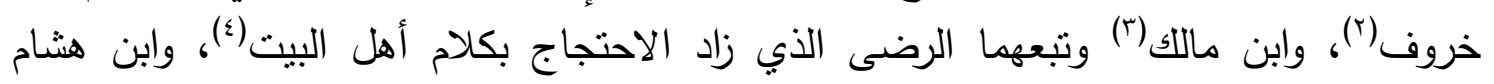
الأنصاري (0).

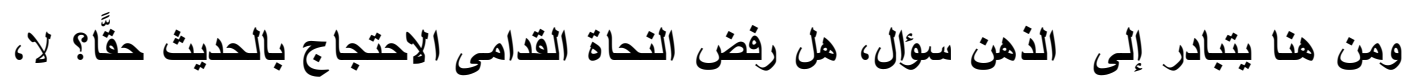

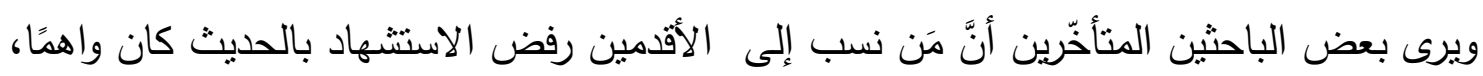

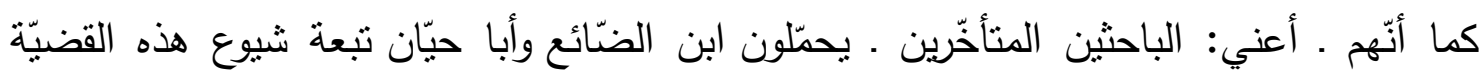

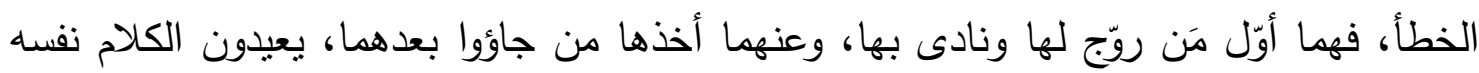
ويكررّونه من دون تمحيص.

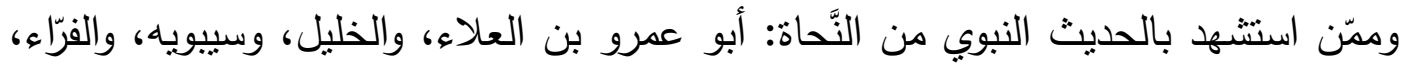

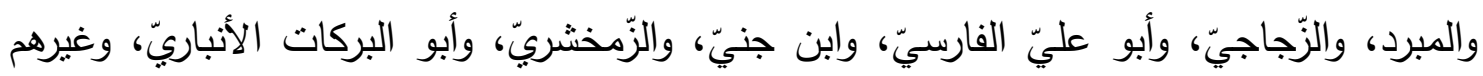

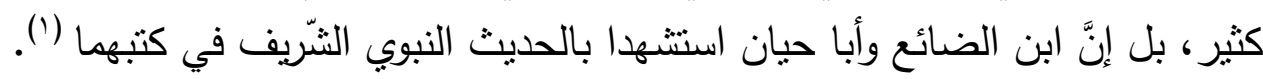
(1) ينظر : مجموعة القرارات العلمية ب، مجمع اللغة العربية من الدورة الأولى إلى الدورة الثامنة والعثرين صد

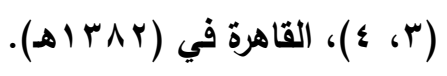

(ץ) ينظر: شرح جمل الزجاجي لابن خروف، تحقيق: سلوى محمد عمر عرب (1 / • 1 ) جامعة أم القرى ـ مكة

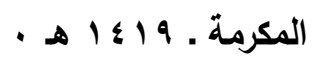

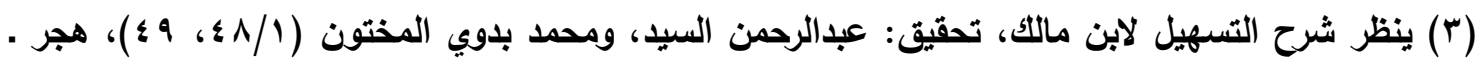

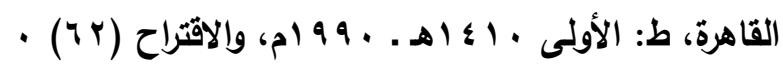

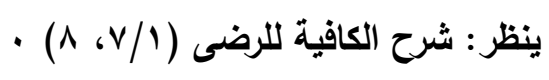

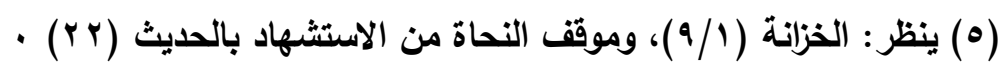


وقد ذكرت هذه الآراء الثناثة لأبين موقف الثارح من الاستشهاد بالحديث؛ حيث أنه لم

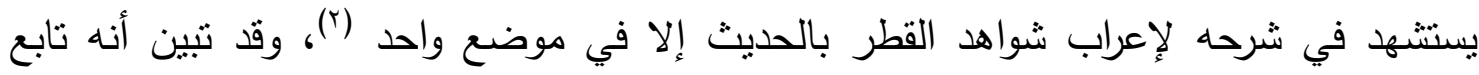
المذهب الأول، وهم المانعون للاستتهاد بالحديث النبوي الثريف.

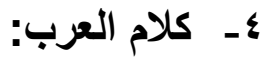

وأما كلام العرب شعرا ونثرا، فيحتج بما ثبت عن الفصحاء الموثوق بعربيتهم، ثم الاعتماد

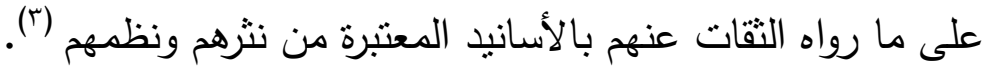

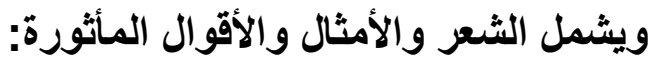

الثعر في اللغة واحد الأشعار ، وهو في الأصل اسم للعلم الدقيق في قولهم ليت شعري. وسمى الثاعر شاعراً لفننته ودقة معرفته".

وفي اصطلاح الأدباء هو كما قال ابن خلدون: "الكلام الموزون المقفى، ومعناه الذي تتكون

$$
\text { أوزانه كلها على روي واحد وهو القافية"(؛). }
$$

ولقد احتفي النحويون واللغويون بالثعر العربي أيما احتفاء، واهتموا به عن غيره في تأصيل

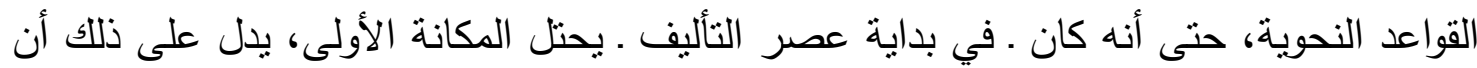
كتاب سيبويه استشهد فيه بالثعر بما يقرب من نحو ألف وخمسين بيتا...

(1) ينظر ذلك بالتفصيل في: موقق النحاة من الاستثهاد بالحديث د/ خديجة الحديثي ( ؟ ـ ـ 9 ( ).

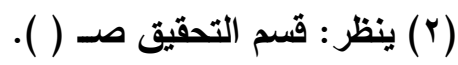

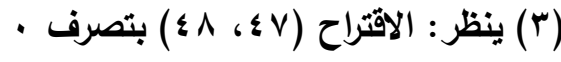
(؛) ينظر: الثعر في ضوء الثريعة الإسلامية لمحمد عبد الرحمن شميلة الأهدل(صد 9 1) - الجامعة

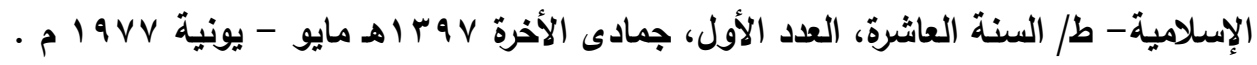




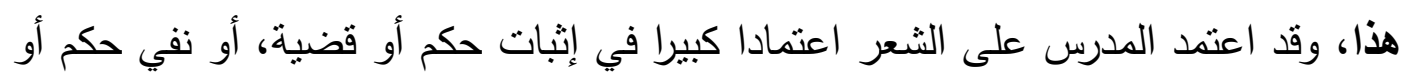
قضية، أو للاستئناس به في أمور أخرى.

وقد استشهد المدرس في هذا الكتاب لشعراء مختلفين، فقد استشهد بشعر الجاهليين، وبشعر المخضرمين، وبشعر الإسلاميين... هذا وقد تنوع استشهاده بالشعر : فأحيانا يذكر صدر البيت، ومن ذلك قوله في هذا الثشاهد:

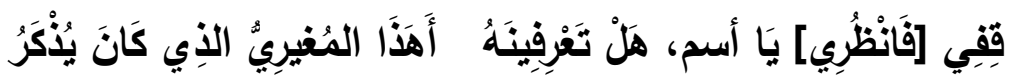

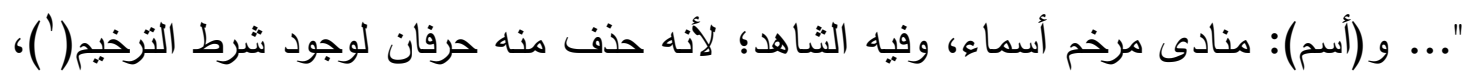

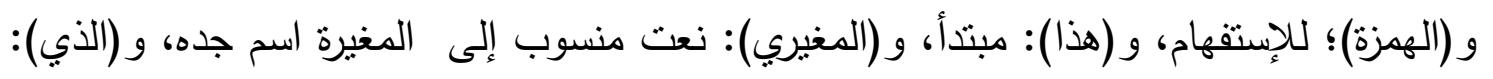
خبره، وجملة (كان يذكر): صلته، والجملة: بدل من الأول، كقوله:

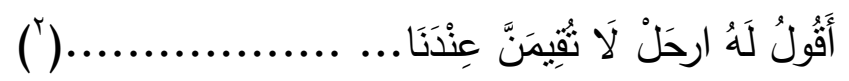

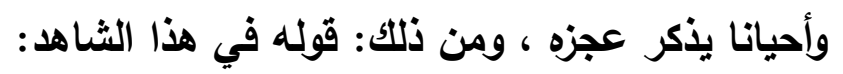

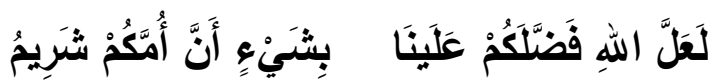

فقال:"... وقد أطبقت الفحول، وتلقاه الجماعة بالقبول على أن (رجل): في "رب رجل كريم لقيته":

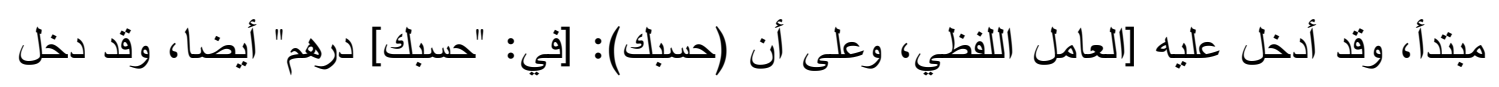
عليه] ذلك على أنه صرح بنظير هذا الإعراب العلامة الكافيجي فقال وأصاب في قوله:

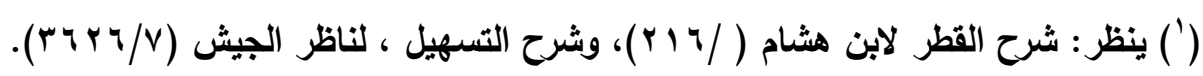

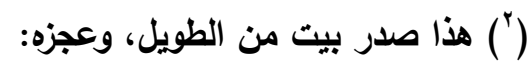

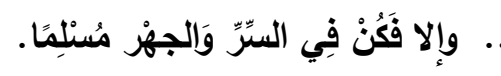

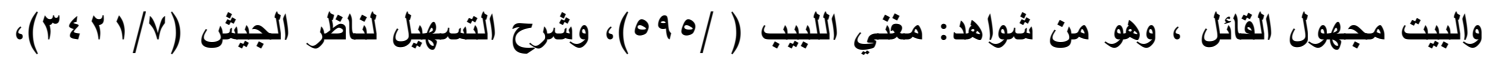

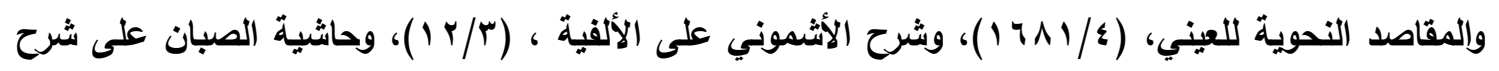

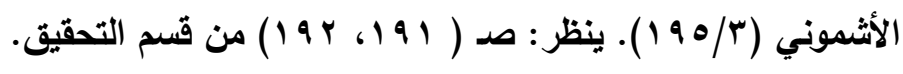




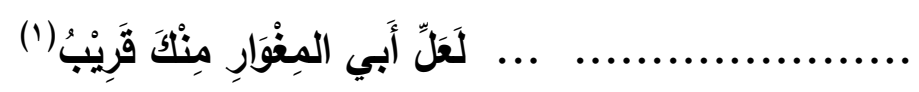

مجرور "لعل" في موضع رفع بالإبنداء يدل على [ذللك] في ارتفاع ما بعده على الخبرية، ف"أبي فئي

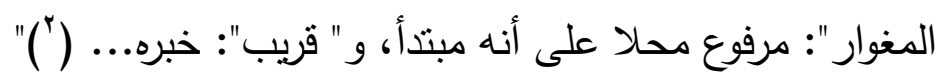

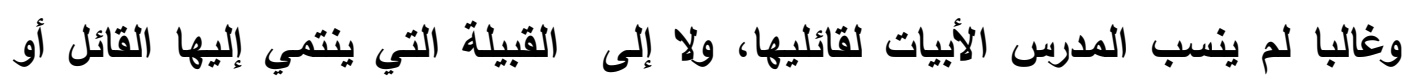

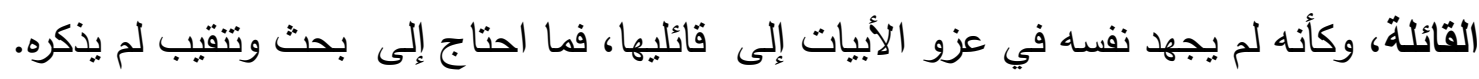

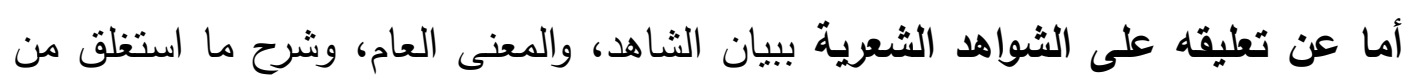

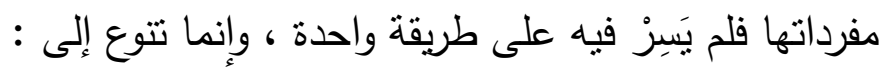

تارة يأكر البيت ولم يتعرض لله بأي تعليق، ولعله اعتمد في ذلك على القارئ في فهمه

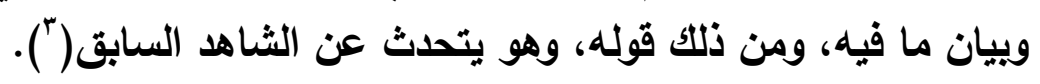
هذا، وذكره الأبيات دون أن يعلق عليها بأي نوع من التعليق هو القليل الغالب عنده، هذا

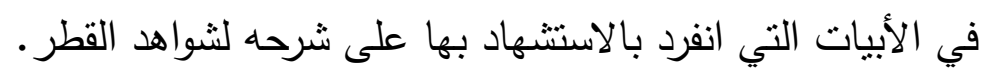

\section{(1) عجز بيت من بحر الطويل، وصدره:}

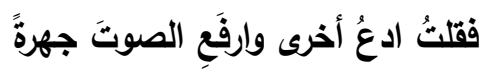

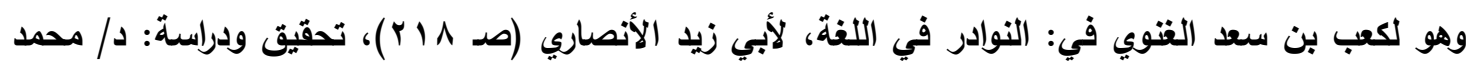

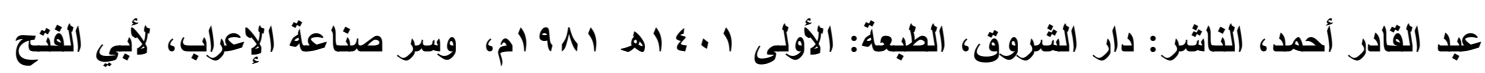

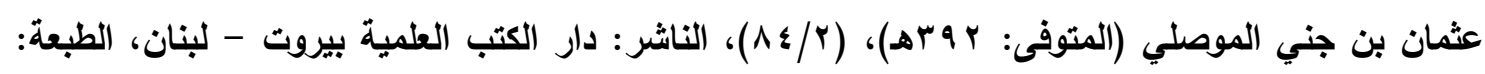

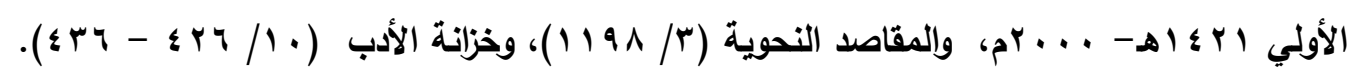

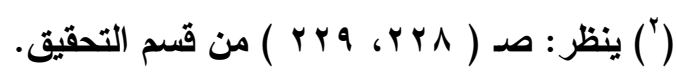

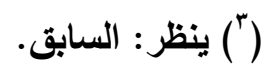


وتارة يعلق على بعض الأبيات التي انفرد بالاستثهاد بها، وهو الكثير الغالب عنده. الأمثال

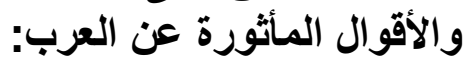

المنثور من كلام العرب أوسع دائرة من الكلام المنظوم؛ حيث إنه لا يتقيد بوزن ولا قافية تحمله على ارتكاب الضرورة والتي من شأنها أن تخالف القاعدة النحوية.

ومع ذلك فإن الثعر كان أكثر ذيوعا من النثر؛ لما يتمتع به من وزن وجرس يجعل الإنسان يتقبله بسهولة ويسر .

يللل على هذه الحقيقة ابن رشيق قائلا: "ما تكلمت به العرب من جيد المنتور أكثر مما

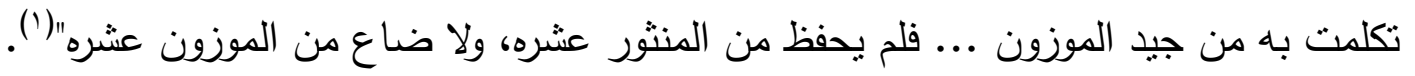
لكن السؤال: هل يحتج بكل ما ورد عن العرب في اللغةّ؟ .

والجواب عن ذللك: نعم؛ لأن الكلام طالما ثبت عن العرب الفصحاء الموثوق بعربيتهم جاز

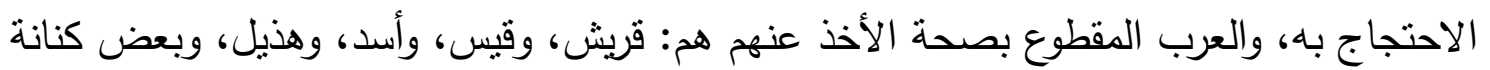
وبعض الطائيين.

والأخذ عن هؤلاء بطريقين:

الأول: المشافهة، والثاني: الاعتماد على ما رواه الثقات عنهم بالأسانيد المعتبرة من نثرهم ونظمه

وقد اعتمد سييويه ـ رحمه الله ـ على هذين الطريقين؛ فهو يسمع عن العرب، ويحكى ـ أيضا

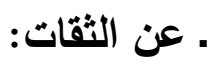

(1) ينظر : العمدة لابن رشيق ( / ب) ط / دار الجيل بيروت، تح/ محمد محى الدين عبدالحميد، الخامسة.

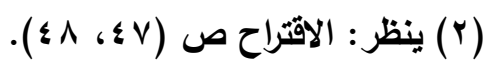


يقول: "وسمعت بعض العرب يقول: "بيس" فلا يخف الهمزة ويدع الحرف على الأصل، كما

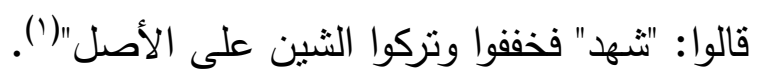

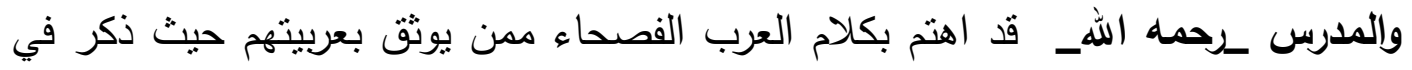

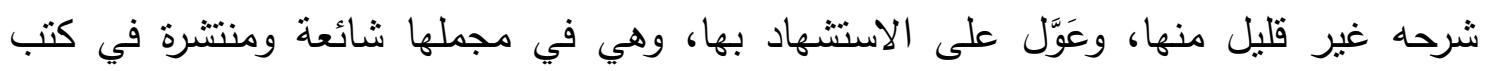
القدامى من النحويين واللغوبين.

وقد استشها بها _أيضا__على إثبات حكم أو قضية أو نفي حكم أو قضية، وقد تنوع

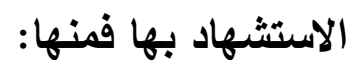

أمثال أو أقوال ذكرت مفردة، أي: لم يُنْكَرَ معها قرآن، ولا حديث ولا شعر : قوله، وهو يتحدث عن أقسام اللام في هذا الثاهد:

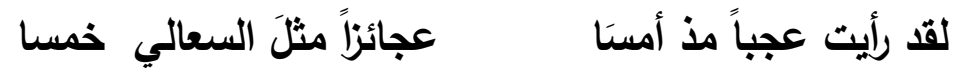
يقول: "... وقد على قسمين: [1]:اسمية، وتستعمل على وجهين [1]: مبنية وهو الغالب؛ لثبهها بقد الحرفية في لفظها، ولكثير من الحروف في وضعها، وإذا أضيفت إلى ياء المتكلم

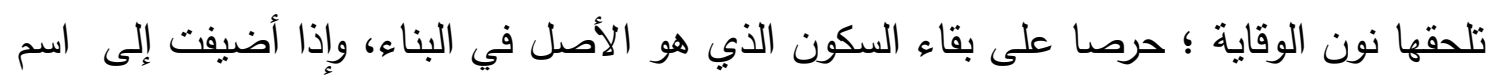
ظاهر نحو: قُّ زيد درهم، تبقي على سكونها.

[ץ]: ومعربة، وهو قليل، فإذا أضيفت إلى اسم ظاهر، ظهر إعرابها، وإلى ياء المتكلم، قدر

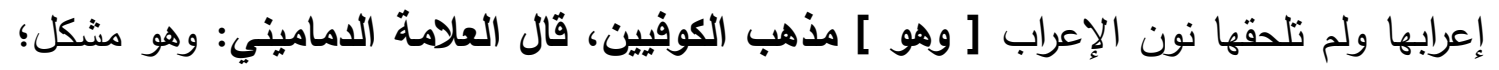

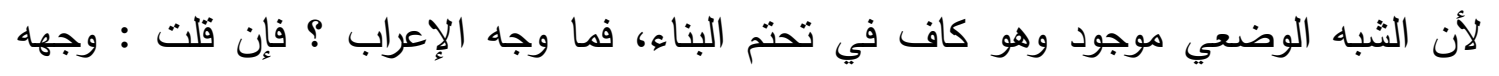

$$
\text { (1) - (1) ينظر: الكتاب (ع / } 9 \text { (1) ). }
$$


ملازمتها للإضافة، قلت: لو صح رافعا لم تبن في: " قُّ زياٍ درهُّ" بالسكون، وهي حالتها الغالبة

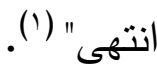

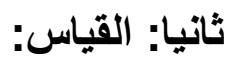

وهو حمل فرع على أصل بعلة (؟)، ونقل السيوطي في الاقتراح (r) عن ابن الأنباري أنه قال في تعريفه: "هو حمل غير المنقول على المنقول إذا كان في معناه" •

وهو معظم أدلة النحو، والمُعَوَّل في غالب مسائله عليه، كما قيل من [الرمل]:

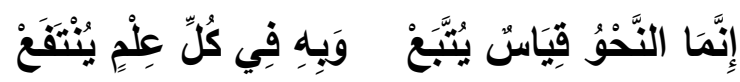
ولهذا قيل في حده: إنه علم بمقاييس مستتبطة من استقراء كلام العرب"(؛).

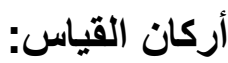

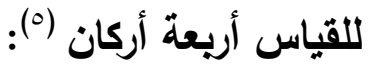

أصل، وهو المقيس عليه، وفرع وهو المقيس، وحكم، وعلة جامعة. ومن شرط الأصل، وهو المقيس عليه ألا يكون شاذا خارجا عن سَنَن القياس،

فما كان كذلك لا يجوز القياس عليه، لا نطقا ولا تركا (†).

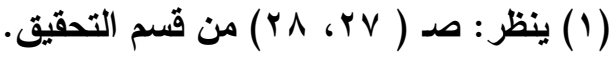

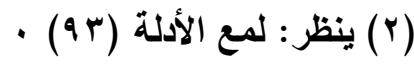

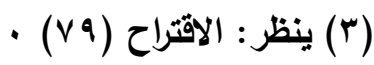

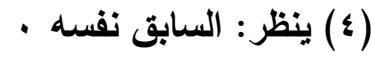

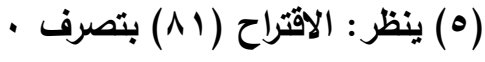

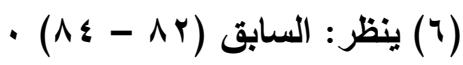


وأما الفرع، وهو المقيس فيشترط فيه أن يكون من كلام العرب، نقل ذلك السيوطي في

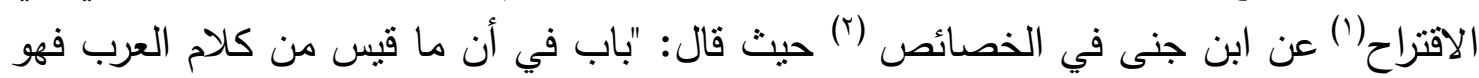
من كلام العرب، هذا موضع شريف، أكثر الناس يضعف عن احتماله؛ لغموضه ولطفه، والمنفعة به عامة، والتساند إليه مقوّ مُجْدِ، وقد نص أبو عثنمان عليه، فقال: ما قيس من كلام العرب فهو

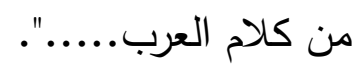

وأما الحكم فإنما يقاس على حكم ثبت استعماله عن العرب بالسماع، أو بالقياس والاستتباط (؟). فالمدرس لم يستدل بالأركان الثلاثة الأولى من القياس في إعرابه لشواهد شرح القطر إلا

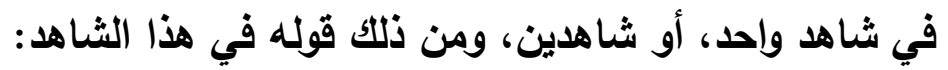

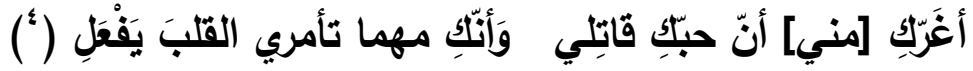

يقول: " (الهمزة): للإستقهام، و (غر): فعل ماضي مبني للفاعل، و (الكاف): مفعوله، و(مني): متعلق به، وعداه بمن، والقياس تعديه بفي؛ لتضمنه معنى الاملاك أي: أغرك كون حبلك مالكا

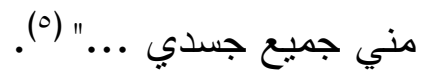

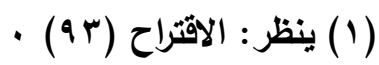

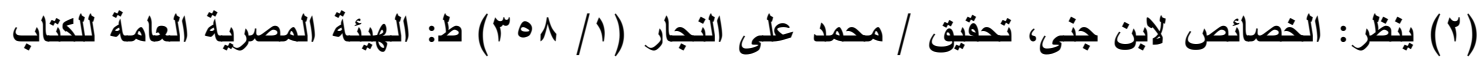

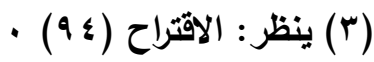

( ) البيت من بحر الطويل، وهو لامرئ القيس من قصيدته المشهورة، إحدى المعلقات السبع، والبيت له في:

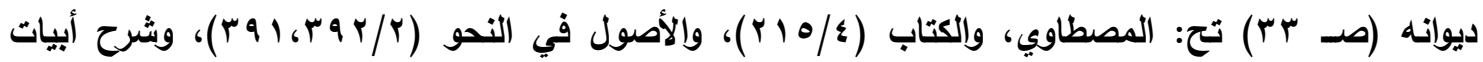

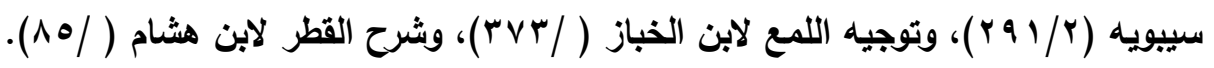

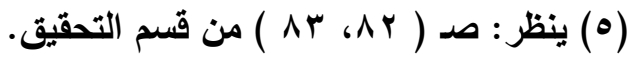


وأما العلة وهي الركن الرابع، فهي: . بكسر العين: المرض وصاحبها معتل، والعِلة: حدث

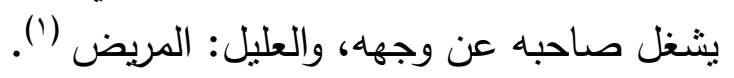

واصطلاحاً: كل وصف حل بمحل وتغير به حاله معا فهو علة، وصار المحل معلولاً كالجرح

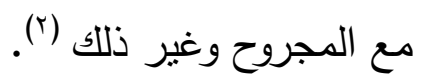

ذكر السيوطي في الاقتراح (r) عن صاحب المستوفي قوله: "إذا استقريت أصول هذه

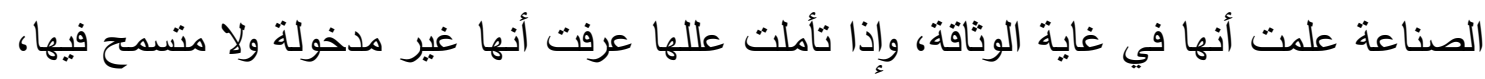

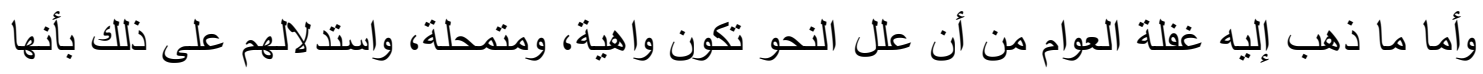

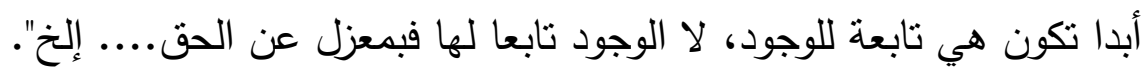

\section{أقسام العلة:}

يقول السيوطي في الاقتراح ())؛ نقلا عن أبى عبد الهه الحسين بن موسى الدينوري في

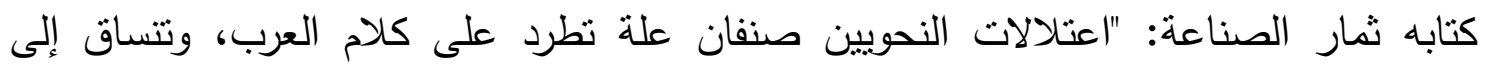

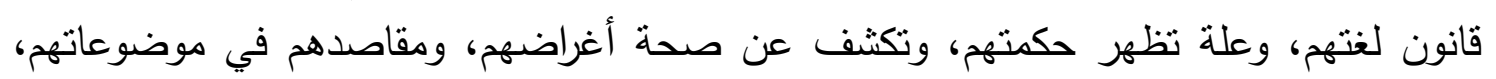

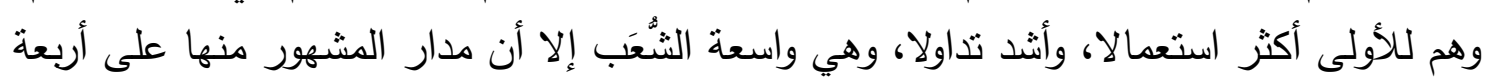

$$
\text { وعشرين نوعا: }
$$

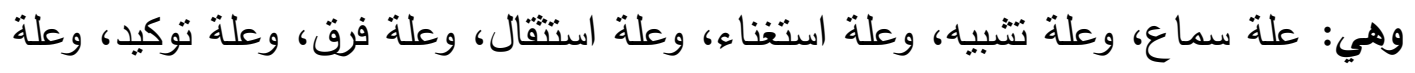

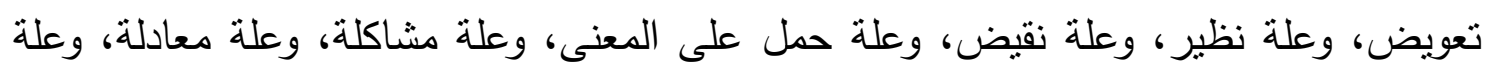

$$
\begin{aligned}
& \text { (1) ينظر : العين (1//1) (ع ل ل). }
\end{aligned}
$$

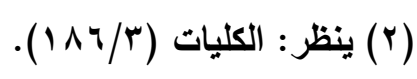

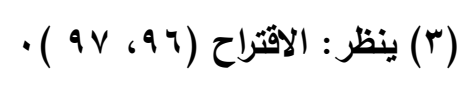

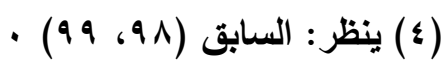


قرب ومجاورة، وعلة وجوب، وعلة جواز ، وعلة تغليب، وعلة اختصار ، وعلة تخفيف، وعلة دلالة

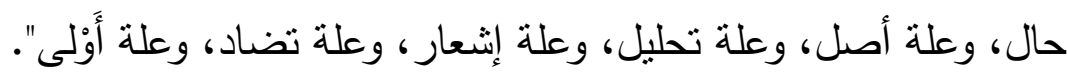

وقد اهتم المدرس باعتلالات النحويين، فجاءت منها على لسانه وفي كتابه هذا لإثبات حكم أو قضية.

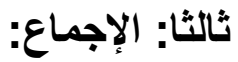

والمراد به: إجماع نحاة البصرة والكوفة، وإنما يكون حجة إذا لم يخالف المنصوص ولا

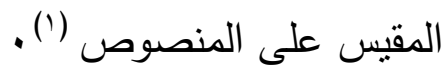
وقد أخذ المدرس بالإجماع، واحتكم إليه في بعض من القضايا وها هي ذي نماذج تؤيد ذلك: قوله ، وهو يتحدث عن أقسام اللام في هذا الثاهد:

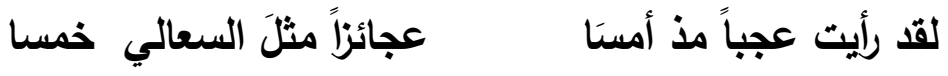

يقول: " اعلم أن (اللام) على قسمين: عاملة، وغير عاملة، فالثانية: على أقسام: أحدها لام

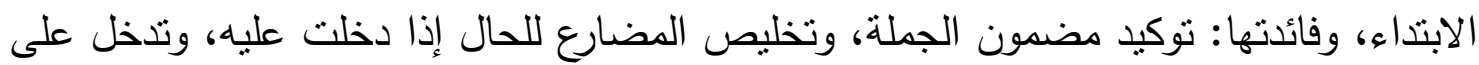

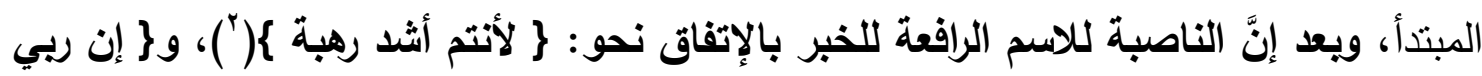

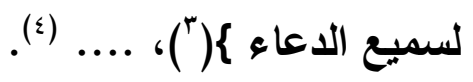

$$
\begin{aligned}
& \text { (1) ينظر : الاقتراح (VT) }
\end{aligned}
$$

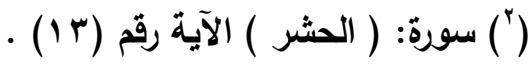

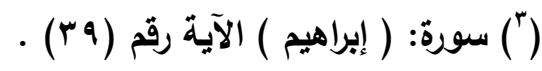

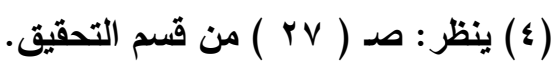




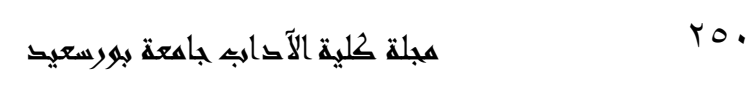

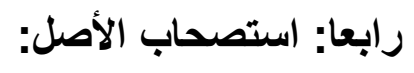

هو من أدلة النحو المعتبرة إذا لم يوجد دليل آخر ينقل عن الأصل.

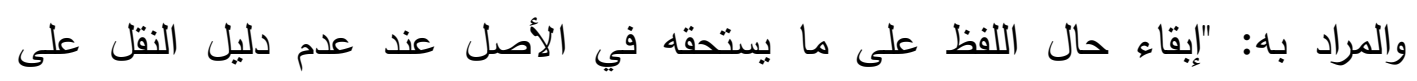
الأصل"(()(') فالمدرس لم بعتمد على استصحاب الأصل في كتابه.

(1) ينظر : الإغراب في جدل الإعراب لابن الأنباري، تحقيق: أ: سعيد الأفغاني صد (؟ ؛ )، ط: الجامعة السورية .

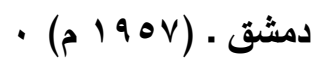

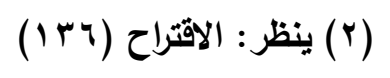

العقد الثالثه كشر / يوليه - 19. مه 